\title{
Meta-cognitive Strategy and Secondary School Students' Achievement and Retention in Chemistry
}

\author{
Theresa M. Udofia Uduak P. Edem \\ Department of Science Education, Faculty of Education, University of Uyo.Uyo
}

\begin{abstract}
The study examined the effect of meta-cognitive strategy (KWL) and secondary school students' academic achievement and retention in chemistry in Uyo metropolis in Akwa Ibom state, Nigeria. Two research questions were raised and two hypotheses formulated to guide the study. The design for the study was a pretest posttest quasi-experimental. Two out of fifteen public secondary schools in Uyo metropolis of Akwa Ibom state were randomly selected for the study. A sample of one hundred (100) SS11 students consisting of 47 boys and 57 girls from two intact classes were drawn from the selected schools. Two validated instruments tagged chemistry achievement test (CAT) and chemistry retention test (CRT) containing 25 items each were used to collect data. The reliability co-efficient of CAT and CRT were determined using test-retest method. The data obtained were analysed using Pearson Product Moment Correlation (PPMC) and the reliability coefficients of 0.81 for CAT and 0.77 for CRT were obtained respectively. Mean and standard deviation were used to answer research questions and analysis of covariance (ANCOVA) was used to test hypotheses at 0.05 level of significance. The findings showed a significant difference in achievement and retention scores of chemistry students taught alkanols using KWL and those taught with expository strategy. It is recommended that chemistry teachers use Know- What and Learn meta-cognitive strategy during instructional delivery to make teaching and learning more participatory, self monitoring and self evaluating so as deeper to understanding and retention of chemistry concepts.

Keywords: Meta-cognitive strategy, Know- What and Learn, expository, chemistry Achievement, self monitoring, Retention

DOI: $10.7176 / \mathrm{CMR} / 11-3-04$

Publication date:March $31^{\text {st }} 2019$

\section{Introduction}

Effective and interactive instructional delivery play significants role in the teaching-learning process. Successful teaching of chemistry therefore, calls for flexible pedagogy for effective self- monitoring and deep understanding of concepts. Thus the method a teacher uses can make or mar students' grasp of the lesson. According to Onwioduokit (2013) teachers' choice of instructional strategy is to a large extent dependent on a number of variables ranging from students' background, aspiration, teachers' experience, and intelligence, age of students, available resources and concept under consideration. This therefore means that chemistry teachers have to employ appropriate teaching strategies that suit the teaching -learning situation in order to bring about meaning learning outcomes.

Know-What and Learn (KWL) meta-cognitive strategy is a student-centered strategy that consists of introduction (activation of prior knowledge), monitoring (identification of what to learn), reflection (recalling what have been learned) and evaluation. It is a strategy that provides students with the ability to think, know how to process information, coordinate the learning process and apply the knowledge in solving problems. It is an active teaching and learning strategy. Tok (2013) note that the strategy which consists of three basic stages of accessing previous knowledge, determining what one wants to know and recalling what is learned.

Flavell (2006) draws the distinction between cognitive and meta-cognitive strategies thus; whereas cognitive strategies are used to facilitate cognitive progress (execution of the learning process), meta-cognitive strategies are implemented to help students plan, monitor, reflect throughout the learning process and evaluate on learning outcomes. The strategy attaches importance to students being totally engaged in knowledge construction and monitoring of learning outcomes. The use of KWL strategy encourages students to be mentally active during the learning process by developing suitable questions and trying to find possible answers to the given topic. It also helps students to develop skills for organizing prior knowledge about the topic as well as evaluate the success of the learning. Nbina (2012) opined that meta-cognitive strategy is an effective strategy for teaching chemistry because it helps students acquire necessary skills for efficient and effective learning.

Retention is a variable that plays a major role in, comprehension and application of chemistry concepts to everyday life. Students' retention is closely related to academic performance and is measured using students' achievement. Kurumeh, Onah and Mohammed (2012) reported that students' retention in science depends on instructional modality adopted by teachers. Similarly, Okebukola (2009) asserted that any instructional mode, which elicits adequate students' participation, has a profound effect on retention. This implies that student retention ability could improve if chemistry teachers employ strategies that would enhance effective assimilation of information towards meaningful understanding and retrieval of facts when needed.
\end{abstract}


Statement of the Problem

In spite of the significant role of chemistry in industrial and technological development of the society, students of that discipline have continued to experience a decline in academic performance especially in external examinations like NECO and WASSCE in Nigeria. Several factors have been identified for the poor achievement in chemistry among them and theses include are poor meta-cognitive ability, study habit, gender influence and ineffective instructional method adopted by teachers. Of all these, instructional strategies employed by teachers appear overbearing because of its facilitating effect on understanding and retention of facts. This study, therefore, examined the effect of Know- What and Learn (KWL) meta-cognitive strategy on students' academic achievement and retention in alkanol chemistry in secondary schools in Uyo metropolis in Akwa Ibom State.

\section{Research Questions}

1. What is the difference in the mean achievement scores of chemistry students taught alkanols using KnowWhat and Learn (KWL) meta-cognitive strategy and those taught with expository strategy?

2. What is the difference in the mean retention scores of chemistry students taught alkanols using KnowWhat and Learn (KWL) meta-cognitive strategy and those taught with expository strategy?

\section{Research Hypotheses}

1 There is no significant difference in the achievement of chemistry students taught alkanols using KnowWhat and Learn (KWL) meta-cognitive strategy and those taught with expository strategy.

2 There is no significant difference in the retention scores of chemistry students taught alkanols using KnowWhat and Learn (KWL) meta-cognitive strategy and those taught with expository strategy?

\section{Methodology}

The pretest - posttest quasi-experimental research design was adopted in this study.

\section{Sample and Sampling Technique}

The target population consisted 4795 students from the fifteen co-educational public secondary schools in Uyo Metropolis of Akwa Ibom State. Two schools were randomly selected for the study. A sample of one hundred (100) SS2 students (47 males and 57 females) was drawn from two intact classes from the selected schools. The selected schools were randomly assigned to experimental and control groups. The experimental group was taught with Know-What and Learn (KWL) meta-cognitive strategy while the control group was taught using expository strategy.

\section{Instrument for data collection}

Two instruments Chemistry Achievement Test (CAT) and Chemistry Retention Test (CRT) were developed and used to collect data. The Chemistry Achievement Test (CAT) contained 25 multiple choice questions based on the concept of alkanols and the Chemistry retention test (CRT) was a reshuffled version of the CAT. Each question had four points response options of A, B, C and D with only one correct answer.

\section{Validity and Reliability of the Instruments}

The CAT and CRT were submitted to three validates in the Department of Science Education, University of Uyo, Uyo and two chemistry teachers teaching in the public schools to cross-check the content and appropriateness of the items considering the class of students and objectives of the study. The reliability co-efficient of CAT and CRT were determined using test-retest method. The instruments were administered to 20 students in the study area that were not part of the main study. The data obtained were analysed using Pearson's Product Moment Correlation (PPMC). The reliability coefficients of 0.81 for CAT and 0.77 for CRT were obtained respectively.

\section{Experimental Procedures}

The study took seven weeks with two weeks for training and administration of pretest and five weeks intensive teaching and posttest administration. One validated researcher-developed lesson package based on three different topics on alkanol was used to teach the experimental and the control groups. The research assistants in the experimental group were made to understand and master the features of Know- What and Learn as follows;

(a) Assessing previous knowledge through brainstorming. The "KNOW'" phase in KWL.

(b) Determining what students wants to know. The "WHAT" phase in KWL.

(c) Applying what is learned. The 'LEARN' 'phase in the KWL. After the training, the teachers in both experimental and control groups exposed the students to pretest followed by teaching for four weeks and post test examination in the fifth weeks. 
Data Analysis

The data collected were analysed using Mean, Standard Deviation and Analysis of Covariance (ANCOVA). All the hypotheses were tested at 0.05 level of significance.

Table 1: Mean and Standard Deviation of Chemistry Students' Achievement taught using KWL and Expository strategies.

\begin{tabular}{lllllll}
\hline \multirow{2}{*}{ Strategy } & \multicolumn{3}{c}{ Pretest } & \multicolumn{2}{c}{ Posttest } & \multicolumn{2}{c}{ Remarks } \\
& $\mathrm{N}$ & $\mathrm{X}$ & $\mathrm{SD}$ & $\mathrm{X}$ & $\mathrm{SD}$ & Mean difference \\
\hline KWL & 50 & 3.36 & 1.14 & 22.58 & 1.56 & 19.22 \\
Expository & 50 & 2.54 & 0.73 & 13.20 & 3.14 & 10.66 \\
\hline
\end{tabular}

As presented in Table1, the mean achievement scores of students' pretest and posttest scores taught alkanols using KWL are 3.36 and 22.58 respectively while students taught using Expository method scored 2.54 and 13.20 respectively. The mean gain scores of 19.22 and 10.66 for students taught using KWL and Expository strategy indicate that KWL was more effective than Expository method. The standard deviation of students' pretest and posttest scores alkanols using KWL(1.14 and 1.56) and Expository (0.73 and 3.14) further reveals that students benefited more from KWL than in Expository group.

Table 2: Mean, Standard Deviation and Mean Difference of Students' Posttest and Retention Scores Taught Using Know- What and Learn and Expository Strategies.

\begin{tabular}{lllllll}
\hline \multirow{2}{*}{ Strategy } & \multicolumn{3}{c}{ Posttest } & \multicolumn{2}{c}{ Retention Test } & \multicolumn{2}{l}{ Mean } \\
& $\mathrm{N}$ & $\overline{\mathrm{X}}$ & $\mathrm{SD}$ & $\overline{\mathrm{X}}$ & $\mathrm{SD}$ & difference \\
\hline Know- What and Learn & 50 & 22.58 & 1.56 & 21.94 & 1.83 & -0.64 \\
Expository & 50 & 13.20 & 3.14 & 10.34 & 3.12 & -2.86 \\
\hline
\end{tabular}

As shown in Table 2, the mean scores of students' posttest and retention scores taught alkanols using KnowWhat and Learn are 22.58 and 21.94 while students taught using Expository method are 13.20 and 10.34 respectively. From the mean difference in the retention test, KWL has the least value (-0.64) implying that KWL enhanced students' retention better than expository strategy.

Hypotheses Testing

Table 3: Analysis of Variance of Posttest Scores of Students' Academic Achievement in Chemistry Using Pretest as Covariate.

\begin{tabular}{llllll}
\hline Source of Variation & \multicolumn{1}{c}{$\mathrm{SS}$} & $\mathrm{df}$ & \multicolumn{1}{c}{$\mathrm{MS}$} & $\mathrm{F}_{\text {cal }}$ & P-value $_{\text {cal }}$ \\
\hline Pretest & 528.173 & 1 & 528.173 & $88.10^{*}$ & .000 \\
Strategy & 1694.112 & 1 & 1694.112 & $282.59^{*}$ & .000 \\
Residual & 581.51 & 97 & 5.995 & & \\
Total & 2803.790 & 99 & 28.321 & & \\
\hline
\end{tabular}

* $=$ Significant at .05 level of significance

The result in Table 3 shows that the calculated P-value (.000) of Strategy is less than the alpha level (.05). Therefore, the null hypothesis is rejected. This implies that there exists significant difference in the achievement of chemistry students taught alkanols using KWL and those taught with expository strategy.

Table 4: Analysis of Variance of Students Retention Scores Based on Strategy Using Posttest Scores as Covariate

\begin{tabular}{lcclll}
\hline Source of Variation & $\mathrm{SS}$ & $\mathrm{df}$ & \multicolumn{1}{c}{$\mathrm{MS}$} & $\mathrm{F}_{\text {cal }}$ & P-value $_{\text {cal }}$ \\
\hline Posttest & 3621.540 & 1 & 4453.79 & 1679.30 & .000 \\
Strategy & 102.408 & 1 & 71.93 & 27.12 & .000 \\
Residual & 296.093 & 97 & 2.65 & & \\
Total & 4020.041 & 99 & 33.46 & & \\
\hline
\end{tabular}

${ }^{*}=$ Significant at .05 level f significance

As presented in Table 4, the calculated P-value (.000) of strategy is less than the alpha level (.05). Therefore, the null hypothesis is rejected. This implies that there exists significant difference in the mean retention scores of chemistry students taught using alkalnols Know- What and Learn and those taught with expository strategy.

\section{Discussion of Findings}

The result showed that Know- What and Learn was more effective at enhancing students achievement in chemistry alkanols than expository method. This findings is in agreement with the of Zekri and Mirjana (2016) that KnowWhat and Learn meta-cognitive strategy significantly enhanced academic achievement and meta-cognitive ability of secondary school students in physics. The findings of the study is also in tandem with those of Vijaya and Jinto (2008), that Know What Learn meta-cognitive strategy is significantly effective at enhancing the academic achievement and meta-cognitive ability of secondary school students. The result gave credence to Coutinbo (2007) that meta-cognitive activity improve critical thinking, reasoning, and problem-solving skills of students. This better performance by students taught alkanol using KWL meta-cognitive strategy could be due to students' 
participation in the learning process through self monitoring, reasoning, reflecting and evaluation of personal progress.

The findings also revealed a significant difference in the mean retention scores of chemistry students taught alkanols using KWL and those taught with expository strategy. The findings is consistent with previous findings of Tok (2013) to the effect that students who practiced monitoring and reflective skills of KWL strategy performed significantly higher in mathematics test than students who did not use the strategy. The finding is also in line with that of Ozden and Ahmet (2010), who found a significant difference in retention test in self monitoring aspect of meta-cognitive strategy. According to Udofia (2015) any method or material that aids learning can enhance assimilation and comprehension resulting in improves retention of facts.

\section{Conclusion}

The study determined the effect of Know- what and learn meta- cognitive strategy on students' achievement and retention in alkanol chemistry. From the findings it is concluded that meta-cognitive strategy, KWL is effective in promoting reflective thinking, self-monitoring and self-assessment on what the students are thereby resulting in enhanced academic achievement. The strategy can also enhance students' retention of facts in chemistry than the expository method. It is therefore apt for chemistry teachers to utilize the strategy for impactful teaching. Students should be encouraged to be actively involved in learning activities through self monitoring, asking and answering questions, solve problems, reflecting on and evaluating what is learnt for better retention and academic achievement.

\section{Recommendations}

Efforts to improve instructional delivery by chemistry teachers through the use of students-centered instructional strategies that promote self monitoring and self evaluation have been advocated by chemistry educators. Professional bodies like Science Teachers' Association of Nigeria (STAN), Curriculum Organization of Nigeria $(\mathrm{CON})$ and others should organize regular seminars, conferences and workshops for chemistry teachers to assist in meaningful development of knowledge and ability of utilizing the strategies effectively. Such seminars and workshops should integrate know-what and learn strategy for the teachers to acquire the skills involved in using meta-cognitive strategies for better student' learning outcomes.

\section{REFERENCES}

Coutinbo, S. A. (2007). The relationship between goals, meta-cognition and academic success. Educate, 7(1), 3947.

Flavell, J. H. (2006). Meta-cognition and cognitive monitoring: A new area of cognitive-development inquiry. American Psychologist, 34, 906-911.

Kurumeh, M., Onah, F. and Mohammed, A. (2012) Improving Students' Retention in Junior Secondary School Statistics using the Ethno-mathematics Teaching Approach in Obi and Oju Local Government Area, of Benue State, Nigeria. Greener Journal of Educational Research, 2(3): 54-62.

Nbina, B. V. (2012) Effect of instruction in Meta-cognitive self-assessment strategy on chemistry students' selfefficacy and achievement. Academic Arena, 2(11):1-10

Okebukola, P. A. O. (2009). Some factors in students under achievement in Senior Secondary School Science subject. Journal of Science Education, 9(4): 122-126.

Onwioduokit, F.A. (2013). The ordeal of science teaching in the contemporary society: A Need for Paradigm shift for The New Generation. 36 ${ }^{\text {th }}$ Inaugural Lecture Series Delivered in the University of Uyo, 1st January, 2013.

Ozden, D. and Ahmet, D. (2010). The Effect of Meta-cognitive Strategies Instructed through Cognitive Coaching on the Meta-cognitive Skills and retention in 6th Grade Social Studies Lesson. Elementary Education online, $9(1): 106-127$.

Tok, S. (2013). Effects of the Know-Want-Learn strategy on students' mathematics achievement, anxiety and metacognitive skills. Metacognition Learning 8: 193-212

Udofia, T. M. (2015). Effect of elaborative -generative and exploratory discovery instructional strategies on secondary school students' learning outcomes in chemistry in Akwalbom State, Nigeria. Unpublished Ph.D Thesis. Department of Teacher Education. University of Ibadan, Ibadan

Vijaya, K and Jinto, M. (2014). Effectiveness of KWL Metacognitive Strategy on Achievement in Social Science and Metacognitive Ability in Relation to Cognitive Styles.International Journal of Educational Research and Technology, 5 (1) : 92-98

Zekri, Z. and Mirjana S. (2016) . The effects of the Know-Want-Learn (KWL) strategy on primary school students' meta-cognition and physics achievement. Journal of Subject Didactics, 2016 1, (1): 39-49. 